\title{
Paediatric Surgical Outreach to Papua New Guinea: Initial Experience
}

\author{
R. Rai' ${ }^{1}$ Jack Mulu², A. S. Jacobsen ${ }^{1}$ \\ ${ }^{1}$ Department of Paediatric Surgery, K K Women's \& Children's Hospital, Singapore \\ ${ }^{2}$ Paediatric Surgical Unit, Port Moresby General Hospital, Korobosea, Papua New Guinea \\ Email: rairambha@gmail.com
}

How to cite this paper: Rai, R., Mulu, J. and Jacobsen, A.S. (2018) Paediatric Surgical Outreach to Papua New Guinea: Initial Experience. International Journal of Clinical Medicine, 9, 697-702.

https://doi.org/10.4236/ijcm.2018.99058

Received: July 20, 2018

Accepted: September 15, 2018

Published: September 18, 2018

Copyright (c) 2018 by authors and Scientific Research Publishing Inc. This work is licensed under the Creative Commons Attribution International License (CC BY 4.0).

http://creativecommons.org/licenses/by/4.0/

\begin{abstract}
This is a report of our early experience in establishing a Paediatric surgical outreach program to Papua New Guinea (PNG) to build capacity and improve care. A Paediatric surgical outreach mission was initiated about 4 years ago in collaboration with Singhealth and PNG along with the multidisciplinary team of health care professionals from Cardiology, Cardiothoracic Surgery, Orthopaedics, Urology, Plastics and Anaesthesia. On each mission trip of 4 - 7 days duration, Singhealth doctors supervise or perform surgeries for complex cases, conduct patient consultations and give lectures to impart knowledge and transfer skills to the local health care community in PNG. In addition, a 6 - 12 months training program in Singapore for PNG doctors has been started. For complex cases which cannot be managed in PNG, there is provision for transfer of patients to Singapore under KKROK fund for further treatment. So far 4 mission trips have been conducted in past 4 years for paediatric surgical unit in Port Moresby General Hospital of PNG focussing on teaching and training of local Paediatric surgeons. Based on evaluation of the Singhealth medical team, there is severe shortage of medical manpower, surgical skill and specialised expertise. Due to lack of intensive care facility, adequate medications and proper medical equipment in the hospital, there are many conditions being left untreated causing high morbidity and mortality among infants and neonates. Such humanitarian work inspires Singhealth towards its global health mission of promoting health equity in responding to the medical needs of PNG through training and leveraging on strength through partnership. In addition, our doctors gain invaluable learning from the exposure, hone their skill as they treat a diversity of cases and are innovative in their treatment options by working in an environment with limited resources.
\end{abstract}

\section{Keywords}

Paediatric Surgery Outreach, Papua New Guinae 


\section{Introduction}

Papua New Guinea (PNG) is a young nation that became independent in 1975 [1]. It is located in Oceania and is composed of the eastern half of the island of Guinea. With a population of nearly 8 million, and more than 800 native languages, cultures and traditions, its main economic activity is farming and harvesting natural resources. The nation is divided into four regions; namely the New Guinea Islands region, Northern region (Momase), Highlands region and Southern region (Papua). It constitutes a total of 22 provinces. The main referral and teaching Hospital (Port Moresby General Hospital) is located in the southern region.

Healthcare in PNG is primarily provided by the government. The country spends about $4.5 \%$ of its gross domestic product on health [2]. A significant portion of this comes from international donations. The doctor to patient ratio is 1:17,068. Apart from there being an absolute shortage of physicians, there is also an issue of uneven distribution of healthcare resources [3] [4] [5]. Nearly $85 \%$ of the population lives in rural areas, but only $50 \%$ of the doctors work outside the capital Port Moresby [6].

\section{Paediatric Surgery at PNG}

General paediatric surgical service were delivered by the general surgeons or by overseas paediatric surgeons during ad hoc visits for many years, until the first Papua New Guinea paediatric surgeon was trained and graduated from the Papua New Guinea Medical School in 2002. Most of surgical training developments have been supported by AusAid as well as Australian surgeons [7]. Currently there are only 4 surgeons in PNG including 2 in PMGH, doing Paediatric Surgery for a population of 8 million. There is no formal curriculum for the Paediatric surgery training program yet, but for general surgery training, there are well structured criteria similar to a British Training program. After completion of general surgical training for 4 years, they are encouraged to do subspeciality training under the higher postgraduate diploma program [8] [9]. Besides doing the specialist training, the surgeon also has to share the emergency workload of adult general surgery.

The Paediatric surgery service is offered at PMGH, Mount Hagen General hospital for the highland regions and Kevieng General hopsital in the new Guinea islands region, where cases are referred from district/peripheral health centres. At the peripheries where there is no paediatric surgeon, all the children's surgery services are delivered by general surgeons including colostomy for anorectal malformation and hirschsprung's disease.

Port Moresby General Hospital (PMGH) is the main specialist medical centre in the country, located in the capital city. It is also the teaching hospital for University of Papua New Guinea's School of Medicine and Health Sciences. The Port Morsby General Hospital has 700 bed capacity of which the paediatric surgical division is given only 10 beds. The main operating theatre composed of 
only 4 operating theatres, where 10 surgical teams squeeze themselves to operate on these 5 days of a week. The number of paediatric surgical procedure can range from 150 - 200 cases per year. They have only 7 beds in ICU which is also shared by adult surgical cases. There is no neonatal intensive care unit.

\section{Initiation of the Outreach Program}

With the limited capacity and needs in mind, an initiative was launched in the year 2014. The main aim of this initiative was to create an outreach program whereby paediatric surgeons from KK Hospital would share their skills to build capacity and improve care in paediatric surgery in PNG.

The initiative was collaboration between Singhealth International Collaboration Office (ICO) and Port Moresby General Hospital (PMGH). The initiative had 3 key elements:

1) Planned outreach surgical trips where surgeons would undertake training visits to PMGH.

2) Exchange fellowship for trainee Paediatric surgeons at KK Hospital.

3) Provision for transfer and management of complex cases under the Regional Outreach Kids Program.

\section{Program Structure}

The program was structured to be a series of visits by a multidisciplinary team from KKH involving Paediatric surgeons, anaesthetists and nurses. Each visit was between 4 - 7 days long. The team mostly consisted of two paediatric surgeons, an anaesthetist accompanying the other adult surgical subspecialty teams from other hospitals under Singhealth. The team stayed close to the airport for operational and safety reasons. They would ferry between the accommodation and PMGH by special transport arrangement. For each trip, the PMGH team would have three main modes of interaction:

1) Operable cases: the team worked up and scheduled complex cases with good training and educational value. The $\mathrm{KKH}$ team usually operated at least 2 sessions with immediate post-operative management done at PMGH under the guidance of the anaesthetist. In all cases, a surgeon from PMGH would either assist or perform under guidance of the KKH team during surgery. This allowed the $\mathrm{KKH}$ team to share specific surgical skills and techniques with the host team.

2) Case management discussions: this would involve grand ward rounds, and discussions on case management of cases admitted to the wards. These discussions gave a different perspective to the PMGH teams thus enriching their management strategy for similar cases.

3) Patient consultations: This involved outpatient consultations for challenging cases brought in by the PMGH team. These sessions were mainly educational and allowed teaching of the local healthcare community as well.

As of June 2018, 4 trips have been completed successfully. Each trip we have managed mostly difficult and complex cases including complex hypospadias, 
extensive lymphangiomas, Hirschprung's disease, anorectal malformations, cloacal anomalies, diaphragmatic hernia, infected cystic airway malformations, parasitic twin etc. Most of cases (90\%) did well and recovered fully.

\section{Challenges and Opportunities}

The outreach program identified many opportunities to contribute to skills development in PNG. As the young nation strives to improve the care for its people, such initiatives can play an important role in helping aspiring trainees in acquiring skill sets that would go a long way in addressing the needs of their communities. The team at PMGH was enthusiastic and eager to maximize their learning. Apart from core surgical capacity development, there is also room for improvement in the support system for the paediatric surgeons.

The program has not been without a fair share of challenges. These can be grouped as being related to the pathology, operational issues and specific areas of need. In a way these also represent opportunities for organizations to help in capacity building.

1) Complex pathology: Usually cases selected for management are complex and difficult cases like Hirschprung's disease, hypospadias, anorectal malformation, cloacal anomaly or complex thoracic lesions with failed previous operations. Because they are technically challenging, most of them need paediatric anaesthetist support and close post-operative monitoring in intensive care.

2) Operational issues: The most important issue is that of limited facilities. The operating room size, equipment and layout were challenging, as was the availability of instruments for paediatric surgery, as opposed to general adult surgical instruments. Radiological and pathology support was also noted to be very limited-primarily because of resource constraints at PMGH.

For operated cases, there is minimal ICU support despite best efforts of the nursing department. There is scope for development of neonatal and children's ICU facilities.

Another aspect is the limitation of skilled manpower. There is a definite need to increase the number of nurses and doctors with a defined formal training program. Once a critical mass of well-trained healthcare staff is available, a multidisciplinary approach would be required for holistic care of children presenting with surgical conditions.

HIV prevalence rates continue to be high in PNG. As such, preoperative screening is not available and needs to be instituted to minimize the risks to the surgeons and nurses.

One unique challenge faced by the surgical teams at PMGH is the lack of follow up and communication with the patient. This is because mostly parents of the children are farmers who wish to resume their daily routines as soon as possible. Besides, the threshold to seek medical care is very high. These factors, coupled with long travel times from the faraway provinces and tough terrain, significantly reduce the number of children returning for scheduled follow ups. 
Foreigners wanting to work in PNG would also need to deal with some restrictions on movement due to security concerns. Any new initiatives would need to address this issue of personnel safety carefully.

3) Specific clinical areas of need:

The absence of a neonatal ICU (NICU) is a very big challenge for managing premature babies of less than 2000 grams. This also then prevents paediatric surgeons from attempting more complex procedures in such children. Complex neonatal surgical cases done include tracheo-esophageal fistula/esophageal atresia (type 3), bowel atresia, gastroschisis and anorectal anomalies requiring colostomy, of some had survived undersstressfull conditions but other did not make it all due to lack of NICU. A good NICU is extremely important to ensure good post-operative care for premature babies who often present with congenital anomalies requiring surgical intervention. The neonatal surgical cases have very high morbidity and mortality rate in perioperative period due to lack of adequate facility and high infection rate.

\section{Insights Gained during the Trips}

Working outside the comfort zone of one's daily practice is not easy. At PMGH, we realized that working with minimal facilities and limited resources forces one to adapt and improvise and innovate based on the needs that arise. Hence they have recorded case of neonatal surgical case, survivor cases such as gastroschisis, tracheo-eosophageal fistula and all anorectal anomallies requiring colostomy. This is a very meaningful insight that we gained from our trips. Besides this, we appreciated the need to plan properly, manage time realistically and anticipate unexpected developments along the way. To perform in the best possible way, we relied on team work and close coordination within the team, and also with our gracious hosts.

So despite the fact that there were resource constraints, the trips so far have been unanimously perceived as being very insightful and gratifying.

\section{Outcomes and Future Plans}

By the end of the fourth trip, the surgical team at PMGH was able to manage some of the index paediatric surgical cases much more confidently. This was achieved by hands-on surgical co-management of cases during the trips. Further, a 6 - 12 months fellowship for trainee paediatric surgeons from PMGH has also been instituted.

Looking forward, there are plans to train other professionals as well. These include other key members involved in the management of paediatric surgical cases, namely paediatric anaesthetists, nurses and neonatologists. There is also a realization for need to train personnel in proper administration of total parenteral nutrition. With a strong team in place, the outcomes are likely to be better.

Apart from manpower training, there are also considerations for building in- 
frastructure in terms of a separate paediatric surgical unit. An improvement in pathology and radiology support is also required. All these would allow a focused delivery of paediatric surgical service to the people of PNG.

\section{Conflicts of Interest}

The authors declare no conflicts of interest regarding the publication of this paper.

\section{References}

[1] World Health Organization (WHO) and National Department of Health (NDoH) of PNG (2012) Papua New Guinea Health Service Delivery Profile.

http://www.wpro.who.int/health_services/service_delivery_profile_papua_new_gui nea.pdf

[2] Thomason, J.A. (1993) Quality of Health Services in Papua New Guinea: What Do We Know? Papua and New Guinea Medical Journal, 36, 90-98.

[3] Healthcare Overview: Papua New Guinea, Madeleine Marsland, Chief of Editorials and Publications PMSA, January 19, 2017.

[4] Martin, J., Tau, G., Cherian, M.N., de Dios, J.V., Mills, D., Fitzpatrick, J., Adu-Krow, W. and Cheng, D. (2015) Survey of the Capacity for Essential Surgery and Anaesthesia Services in Papua New Guinea. BMJ Open, 5, e009841. https://doi.org/10.1136/bmjopen-2015-009841

[5] Dare, A.J., Lee, K.C., et al. (2016) Prioritizing Surgical Care on National Health Agendas: A Qualitative Case Study of Papua New Guinea, Uganda, and Sierra Leone. PLoS Medicine, 13. https://doi.org/10.1371/journal.pmed.1002023

[6] Kaptigau, W.M., Rosenfeld, J.V., Kevau, I. and Watters, D.A. (2015) The Establishment and Development of Neurosurgery Services in Papua New Guinea. World Journal of Surgery, 40, 251-257. https://doi.org/10.1007/s00268-015-3268-1

[7] Watters, D.A. and Theile, D.E. (2000) Progress of Surgical Training in Papua New Guinea to the End of the 20th Century. Australian and New Zealand Journal of Surgery, 70, 302-307. https://doi.org/10.1046/j.1440-1622.2000.01808.x

[8] Kevau, I. and Watters, D.A. (2006) Specialist Surgical Training in Papua New Guinea: The Outcomes after 10 Years. ANZ Journal of Surgery, 76, 937-941. https://doi.org/10.1111/j.1445-2197.2006.03907.x

[9] Dewan, P.A. and Mathew, M. (2000) The Development of Paediatric Surgery in Papua New Guinea. Papua and New Guinea Medical Journal, 43, 60-64. 